\title{
BMJ Global Health Natural disasters, population displacement and health emergencies: multiple public health threats in Mozambique
}

\author{
Vánio A Mugabe, ${ }^{1,2}$ Eduardo S Gudo, ${ }^{3}$ Osvaldo F Inlamea (D) , ${ }^{3}$ Uriel Kitron, ${ }^{4}$ \\ Guilherme S Ribeiro (D) 5,6
}

To cite: Mugabe VA,

Gudo ES, Inlamea OF, et al. Natural disasters, population displacement and health emergencies: multiple public health threats in Mozambique. BMJ Global Health 2021;6:e006778. doi:10.1136/ bmjgh-2021-006778

Handling editor Seye Abimbola

VAM and ESG contributed equally.

Received 30 June 2021 Accepted 15 August 2021

Check for updates

(c) Author(s) (or their employer(s)) 2021. Re-use permitted under CC BY-NC. No commercial re-use. See rights and permissions. Published by BMJ.

${ }^{1}$ Instituto de Saúde Coletiva, Universidade Federal da Bahia, Salvador, Bahia, Brazil ${ }^{2}$ Universidade Licungo, Quelimane, Zambezia, Mozambique

${ }^{3}$ Instituto Nacional de Saúde, Maputo, Maputo, Mozambique ${ }^{4}$ Department of Environmental Sciences, Emory University, Atlanta, Georgia, USA ${ }^{5}$ Instituto Gonçalo Moniz, Fundação Oswaldo Cruz, Salvador, Bahia, Brazil

${ }^{6}$ Faculdade de Medicina, Universidade Federal da Bahia, Salvador, Bahia, Brazil

Correspondence to Dr Guilherme S Ribeiro; guilherme.ribeiro@fiocruz.br

\section{ABSTRACT}

In early 2019, following the 2015-2016 severe drought, the provinces of Sofala and Cabo Delgado, Mozambique, were hit by Cyclones Idai and Kenneth, respectively. These were the deadliest and most destructive cyclones in the country's history. Currently, these two provinces host tens of thousands of vulnerable households due to the climatic catastrophes and the massive influx of displaced people associated with violent terrorist attacks plaguing Cabo Delgado. The emergence of the COVID-19 pandemic added a new challenge to this already critical scenario, serving as a real test for Mozambique's public health preparedness. On the planetary level, Mozambique can be viewed as a 'canary in the coal mine', harbingering to the world the synergistic effects of co-occurring anthropogenic and natural disasters. Herein, we discuss how the COVID-19 pandemic has accentuated the need for an effective and comprehensive public health response in a country already deeply impacted by health problems associated with natural disasters and population displacement.

\section{INTRODUCTION}

Natural disasters have long been associated with humanitarian crises, hampering development and creating huge public health challenges, especially for low-income countries. The main threats to health and wellbeing of affected people include damage to basic infrastructure (eg, water, sanitation and energy supply systems, housing, and health facilities); food shortages and starvation; people displacement; and increased risk of injuries, communicable diseases and ultimately deaths. In contexts where the impact of natural disasters is present, the COVID-19 pandemic further stresses limited resources, creating an even more challenging scenario for the health sector.

Mozambique is a low-income country exposed to multiple climate-related hazards, but with limited capability and preparation in terms of responsiveness. ${ }^{1}$ Each year, millions

\section{Summary box}

- In 2019, Mozambique was hit consecutively by the two deadliest and most destructive cyclones of the last decades of the country's history, following the 2015-2016 severe drought.

- This was the first time in Mozambique's recorded history that a drought, a series of severe cyclones and floods occurred consecutively, pointing to the need for better preparedness to address similar phenomena in the future in the context of climate changes.

- Terrorist attack and the COVID-19 pandemic added new challenges to this already critical scenario.

- The national health system needs to not only respond to emergencies, but also to participate in multisectoral actions to prevent the effects of disasters on exposed populations.

of people are affected by natural disasters country-wide, some on a recurring basis. Droughts, tropical cyclones and floods are the most frequent events (figure 1). Currently, the situation is particularly alarming due to a complex of multiple interconnected shocks in the provinces of Sofala (central region of the country) and Cabo Delgado (northern region of the country).

Sofala Province was hit by a powerful Cyclone Idai in 2019. Almost 2 years later, Cyclones Chalane and Eloise followed the same trail. Cabo Delgado Province was devastated by Cyclone Kenneth in 2019. These two provinces currently host many displaced people and tens of thousands of vulnerable households (the highest number in decades) as a direct consequence of the climatic catastrophes and the massive influx of people following violent terrorist attacks plaguing Cabo Delgado Province since 2017. ${ }^{2}$ The emergence of the COVID-19 pandemic in 2020 added new challenge to this already 


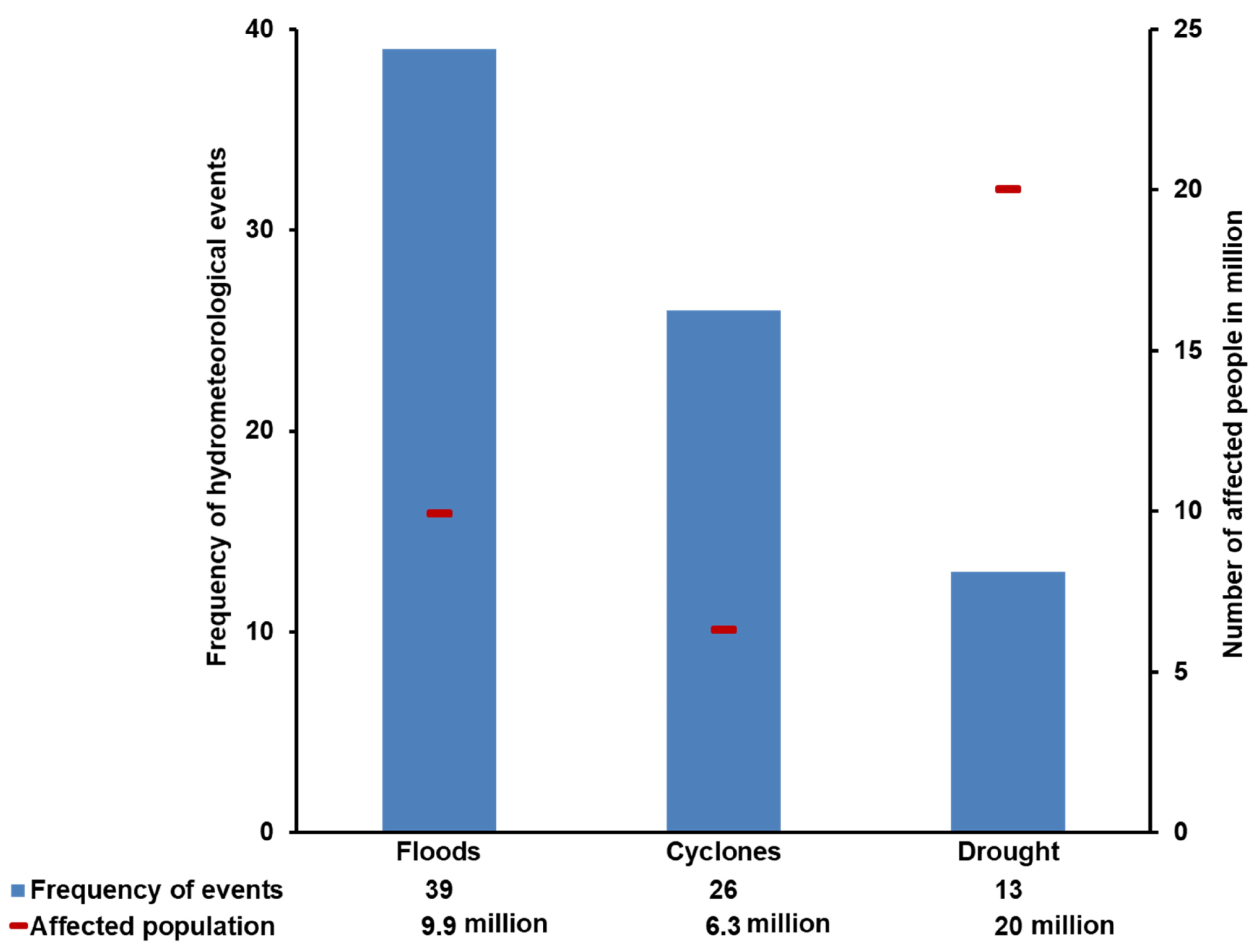

Figure 1 Number of hydrometeorological events and number of people affected in Mozambique between 1956 and 2020. Source of data: EM-DAT (Emergency Events Database), International Disaster Database, Centre for Research on the Epidemiology of Disasters/UCLouvain 2020 Université Catholique de Louvain, Brussels, Belgium. Available at https://public. emdat.be/.

critical scenario, serving as a real test for Mozambique's public health preparedness. Our goal is to discuss how the COVID-19 pandemic accentuated the need for an effective and comprehensive public health response in a country already deeply impacted by health problems associated with natural disasters and population displacement. This discussion may be helpful for policymakers and public health agencies dealing with a syndemic that involves disaster-related health conditions and COVID$19 .^{34}$

We adopted a mixed-method approach to analyse data on damage (patrimonial, economic-financial, environmental, and number of people affected, injured and killed) caused by disasters, with a focus on Cyclones Idai and Kenneth, through the review of official documents and scientific reports produced by agencies involved in the Idai and Kenneth responses; and examine the frequency of diarrhoeal diseases (including cholera), malaria and malnutrition. The target populations of the study were all inhabitants of the districts most affected by Cyclone Idai in Sofala Province (districts of Beira, Búzi, Dondo and Nhamatanda) and by Cyclone Kenneth in Cabo Delgado Province (districts of Macomia and Pemba).

Records of monthly frequency of diarrhoea and malaria data reported in 2018 and 2019 were extracted from the mAlert and Sis-ma platforms of the Epidemiological Surveillance Office, National Institute of Health/Ministry of Health (MoH) of Mozambique. We also obtained data on the frequency of floods, cyclones and droughts, including the number of people affected, and COVID-19 case-reported data from web-based databases such as EM-DAT (Emergency Events Database) and Our World in Data, respectively. Descriptive analysis was employed to calculate the frequencies and percentages. To calculate the cholera attack rate (per 100000 population at risk) and mortality rate at provincial and district levels, we used the 2017 population census data from the National Institute of Statistics.

\section{MOZAMBIQUE OVERVIEW}

Mozambique is located on the Indian Ocean in southeastern Africa, with a coastline of $2515 \mathrm{~km} .^{5}$ The country is downstream from nine major international river basins and in the pathway of tropical cyclones that move across the Mozambique Channel, ${ }^{6}$ making Mozambique one of the countries most prone to flooding and cyclones in the world. $^{78}$

After nearly five centuries of colonisation, Mozambique gained its independence from Portugal in 1975, following a 10-year war for autonomy (1964-1974). With the withdrawal of the Portuguese, the country was beset by extreme poverty and all paths to economic and social development were limited by the lack of qualified human resources. Shortly thereafter, the country entered a civil war that lasted 16 years (1977-1992). Many infrastructures were destroyed and/or abandoned, especially in rural areas, where most of the country's population lives ( $64 \%$ of the 29.5 million inhabitants). ${ }^{9}$ The civil war 
further exacerbated the country's poverty and people's vulnerability. One million people were killed directly; nearly one million died due to indirect consequences, such as starvation and lack or disruption of health services $^{10}$; and about five million were displaced and moved internally to the periphery of major cities (with limited access to basic services and social networks), or became refugees in neighbouring countries. ${ }^{11} 12$

About a decade after the end of the war, Mozambique experienced remarkable economic growth (a record average annual gross domestic product (GDP) growth rate of $7 \%$ over the 2000-2016 period), increased average household income, improved access to basic services, such as education, water, sanitation, electricity and primary healthcare, especially in rural areas, and progress in basic health indicators, such as reductions in maternal and child mortality rates, and expansion of health service coverage and life expectancy. ${ }^{13-15}$ However, the improvements are far from enough, and the country remains one of the poorest and most unequal in the world (United Nations Human Development Index $=0.456$, in 2020), ${ }^{15}$ with serious socioeconomic and security challenges. For example, the health indicators of Mozambicans remain below the average of Sub-Saharan Africa and far below international standards. ${ }^{16}$ The urban-rural inequity in access to health services and quality of healthcare also continues to date. The country's economy remains strongly dependent of natural resources, ${ }^{6}$ with agriculture accounting for a quarter of GDP and serving as the primary source of employment and income for $>70 \%$ of the population, ${ }^{17}$ most of them $(62.9 \%)$ with low purchasing power ( $<$ US $\$ 1.90$ a day to survive).$^{15}$ In addition, since 2017, the northern region of Mozambique has faced violent terrorist attacks, which caused massive destruction of infrastructure and have displaced $\sim 700$ 000 people by the end of March 2021 .

\section{MOZAMBIQUE CURRENT CHALLENGES Perennial droughts}

Mozambique's climate ranges from tropical and subtropical in the north and central regions to dry semiarid steppe and dry arid desert in the south. ${ }^{18}$ Droughts occur in the country in association with most El Niño Southern Oscillation episodes. ${ }^{19}{ }^{20}$ During the $2015 / 2016$ planting season, Mozambique experienced the worst drought in 35 years. ${ }^{21}$ Below-average rainfall in the south and parts of the central region of the country impacted agricultural production that is mostly rain-fed.

Following the drought, and the ensuing loss of harvest, 2.1 million people found themselves in a state of food insecurity in 2016/2017. ${ }^{22}{ }^{23}$ As of December 2018, there were still nearly 1.8 million people suffering from severe food insecurity. ${ }^{24}$ Many low-income families remain in a food crisis situation as a result of further climate disasters in 2018/2019 (rainfall deficits in the south, floods in the central and north regions), which prolonged the stress on food production and availability, and contributed to staple food price inflation. ${ }^{25}$

\section{Impact of Cyclones Idai and Kenneth in Mozambique}

In mid-March 2019, Cyclone Idai and the subsequent flooding affected the central region of the country, with the province of Sofala receiving the worst damage (figure 2A). Six weeks later, in late April, Cyclone Kenneth hit Cabo Delgado Province, in the far north of the country (figure 2B). Both weather systems arrived in the country just before the harvest, causing great losses of crops, and destruction of infrastructure, assets and livelihoods of many families. Combined, the two cyclones destroyed and/or flooded (completely/partially) $>770$ 000 hectares of crops; caused widespread damage to $\sim 280$ 000 houses, $\sim 3200$ classrooms and at least 100 health facilities; displaced nearly 420000 people, of which $\sim 170$ 000 have been accommodated in 164 temporary collective shelters in the central region across Sofala, Manica, Zambézia and Tete provinces, ${ }^{26}$ and in 32 collective shelters in the province of Cabo Delgado ${ }^{24}$; injured nearly 1700 people; killed 648 people; and left $\sim 2.2$ million people in need of humanitarian assistance, ${ }^{24} 28$ in addition to those who were already in need of help following the prior drought.

Cyclones Idai and Kenneth (level 4 on the 1-5 SaffirSimpson wind scale) also damaged the main access roads, disabling support for victims; interrupted the provision of telecommunications and power services at several locations for long periods; further damaged the already deficient supply of drinking water; and limited access to health and sanitation services in affected areas. As of 16 May 2019, the total damage and loss caused by Cyclones Idai and Kenneth had been estimated at US $\$ 2.8$ billion, with damages and losses in production (US\$1191 million), infrastructure (US\$797 million) and social (US\$693 million) sectors. The total recovery and reconstruction needs for all sectors were estimated at US\$3.2 billion, with the health sector alone requiring about US $\$ 235.5$ million for postcyclone recovery. ${ }^{29}$

Following the path of Idai, other cyclones hit Sofala, Chalane on 30 December 2020 and Eloise on 23 January 2021, accompanied by heavy rains and floods, although with less impact than Idai. Yet living conditions and survival of thousands of families, some of which still living in makeshift houses in resettlement centres created after Idai, declined further. The government, through the National Institute for Disaster Risk Management and Reduction (INGD) and its partners, has supported thousands of families, but many of them still lack basic needs (adequate shelter and sanitary provisions, access to food and drinking water), since the resources mobilised are insufficient and accompanied by delays in the disbursement process by international donors.

Even before the cyclones' arrival, about $50 \%$ of the population lived $>20 \mathrm{~km}$ from the nearest health facility, ${ }^{30}$ and with a ratio of 0.84 physicians per 10000 population. ${ }^{31}$ In areas recently affected by cyclones and floods, 

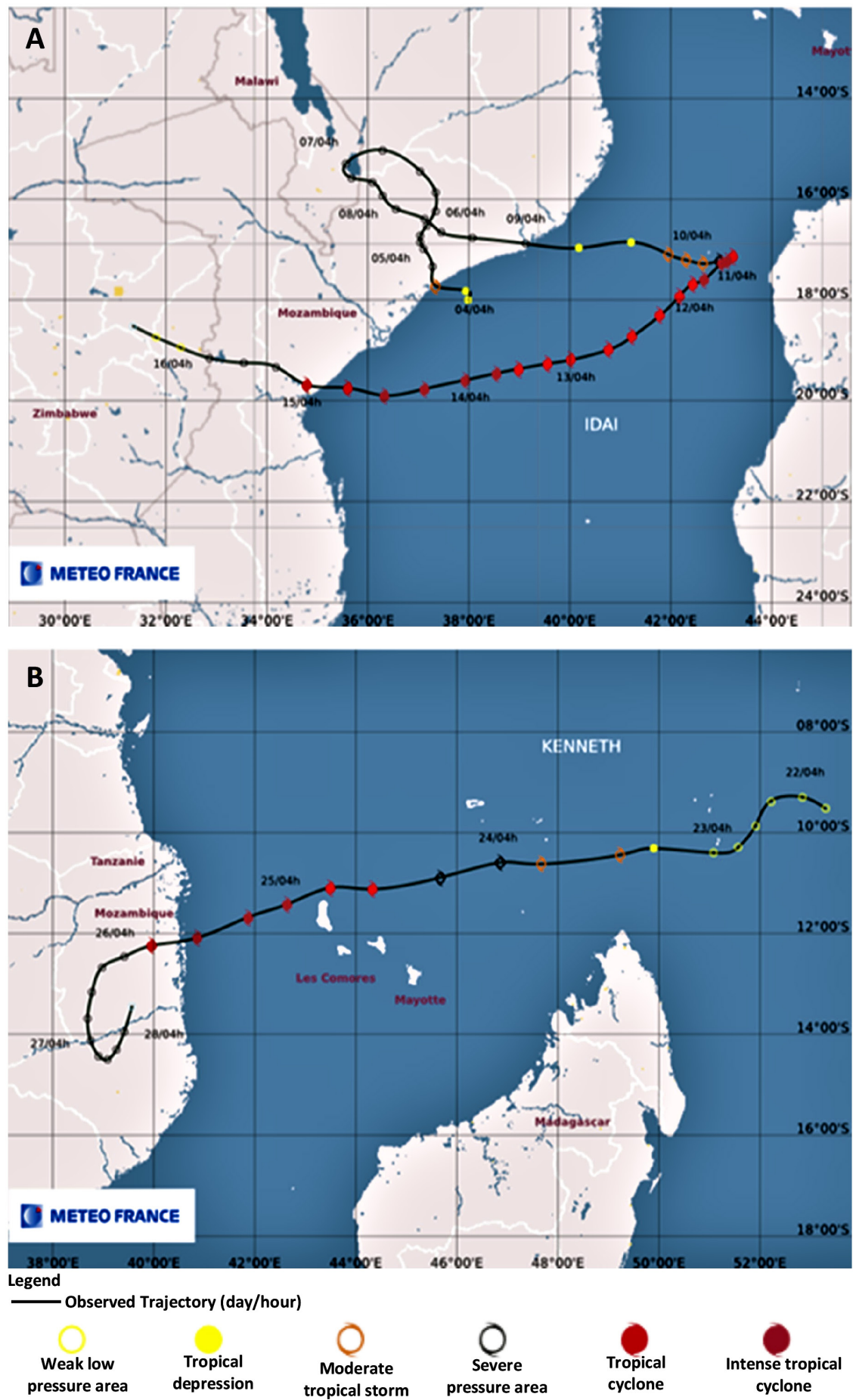

Figure 2 Path of Cyclone Idai (A) in the central region of Mozambique and of Cyclone Kenneth (B) in the far north of Mozambique. (A) Cyclone Idai formed as a tropical depression in the Mozambique Channel on 5 March 2019 and moved over the mainland on 4-9 March, causing heavy rains that resulted in floods in the Mozambican provinces of Zambézia and Tete and in southern Malawi. Idai then moved back eastwards towards the Mozambique Channel, where it gained strength to become a tropical cyclone. On 13 March, Cyclone Idai began moving west again and made landfall during the night of 14-15 March in the central region of Mozambique, affecting the provinces of Sofala, Manica, Zambézia, Tete and Inhambane. It continued to move westwards up to eastern Zimbabwe. (B) Cyclone Kenneth formed in the north of Madagascar and east of the Aldabra Atoll, north of the Mozambique Channel. On 25 April 2019, Kenneth made landfall in Cabo Delgado Province, on the extreme north of the Cabo Delgado and Nampula provinces. Source: Météo-France Réunion. Available at http://www.firinga.com/ influences?influ=mozambique, accessed on 22 April 2021. 
the number of people without access to health has likely increased significantly. In the face of a public health emergency, the response capacity is often delayed, since the sector is underfunded and dependent on external aid, lacks qualified personnel, and the decision-making process depends on hierarchical structure organised by the $\mathrm{MoH}$ for the provincial directorates and from them to the district directorates. When resources are mobilised, the actions implemented are generally short term and directed towards emergency response. They often lack evaluation strategies to assess their impact and to monitor the potential for the emergence of new health problems in the medium and long term.

\section{Diseases following Cyclones Idai and Kenneth}

Even before the cyclones hit Mozambique, there were large gaps throughout the country in the provision of clean drinking water (50\% coverage) and access to improved sanitation facilities (20\% coverage) ${ }^{32}$ Following Idai and Kenneth, the risk of infectious diseases transmission increased due to lack of access to safe water, poor sanitation (including latrines' overflow), contact with stagnant floodwater, greater exposure to the outdoor environment for those who had their houses destroyed, and overcrowding in the camps established to provide shelter to displaced people.

\section{Diarrhoea and cholera outbreak}

Diarrhoeal diseases are common in Mozambique, especially in children $<5$ years of age, for which the mortality rate in 2015 was estimated at 90.8 deaths per $100000 .{ }^{33}$ Due to lack of proper sanitation conditions, cholera hotspots, mainly in the central and northern regions of the country, continue to occur every year, mostly during the wet season. ${ }^{34}$ Following Idai, the frequency of diarrhoea cases recorded in the districts of Beira, Búzi, Dondo and Nhamatanda (Sofala Province) increased 1.2-3.8 times between March and June, compared with the same period in 2018 (figure 3). The frequency of cases peaked 1 week after the arrival of Idai, followed by a sharp decline. On 27 March 2019, the MoH declared an outbreak of cholera in Sofala. By the end of May, at least 6773 cases (attack rate: 571.4 cases per 100000 population) and 8 deaths (case fatality rate: $0.12 \%$ ) were officially recorded in the four hard-hit districts (table 1). ${ }^{35}$ In Pemba and Macomia (Cabo Delgado Province), the frequency of diarrhoea cases throughout 2019 was lower than in 2018. However, a cholera outbreak was officially declared on 2 May, in Pemba, a week after Kenneth's arrival. As of 30 June 2019, 346 cases (no deaths) had been reported in Pemba and in the districts of Metuge and Mecufi (table 1).

A multisectoral and multidisciplinary task force worked to improve active surveillance, case detection and investigation, laboratory diagnosis, and management of suspected cholera cases, limiting the geographical spread of the outbreak and preventing large-scale epidemics. The surveillance was combined with the WASH (water, sanitation and hygiene) intervention and social mobilisation through door-to-door communication strategy to raise families' awareness of the importance of handwashing and safe food handling practices, and boiling or purifying water with products before drinking, and to sensitise the community to join the massive oral cholera vaccination campaign. The strong involvement of the health sector, local authorities and communities themselves enabled the effective coordination of the interventions that were crucial in preventing the spread of disease among vulnerable populations. However, although populations living in areas affected by Cyclones Idai and Kenneth have benefited from the cholera vaccination campaign, the deterioration of environmental conditions in Sofala following the arrival of Cyclones Chalane and Eloise and the mass influx of unvaccinated people towards the city of Pemba have generated an increased risk for new outbreaks.

\section{Malaria}

Malaria is endemic country-wide. ${ }^{36}$ In 2018 , its annual incidence was 305.4 cases per 1000 people at risk, ${ }^{15}$ and in 2019 it was the fourth leading cause of death in the country. ${ }^{37}$ After the landfall of Cyclones Idai and Kenneth, a rapid and massive intervention was implemented to distribute long-lasting insecticidal nets and campaigns were performed to spray indoor insecticide, both of which may have contributed to averting malaria epidemics in the affected districts. Yet an increase in confirmed cases was noted in Búzi, a district of Sofala, between March and June 2019, compared with the same period in 2018 (figure 4).

\section{Malnutrition}

Nutritional deficits resulting from food insecurity are a recurrent problem throughout the country, with direct impact on children's development and childhood mortality (54.0 per 1000 live births),${ }^{15}$ and might induce long-term adverse health consequences, such as increased susceptibility to infectious diseases,${ }^{38}{ }^{39}$ diminished cognitive skills and lower earnings. ${ }^{40}{ }^{41}$ Studies show, for example, that children born in areas affected by drought in Ethiopia suffered from physical development problems associated with malnutrition. ${ }^{42}$ Following Idai and Kenneth, health authorities from Sofala and Cabo Delgado provinces began tracking malnourished children aged 6-59 months. Consequently, from 23 March to 10 October 2019, 160992 children were screened based on mid-upper arm circumference in Sofala Province. Among them, 2345 (1.5\%) were classified as cases of moderate acute malnutrition and $952(0.6 \%)$ as cases of severe acute malnutrition. In Cabo Delgado, of 61 834 children screened from 21 May to 10 October, 1405 $(2.3 \%)$ were classified as moderate acute malnutrition and $302(0.5 \%)$ as severe acute malnutrition. ${ }^{43}$ Just following, between October 2019 and February 2020, it was estimated that $\sim 67500$ children $<5$ years of age were malnourished country-wide, with 6500 suffering severe 

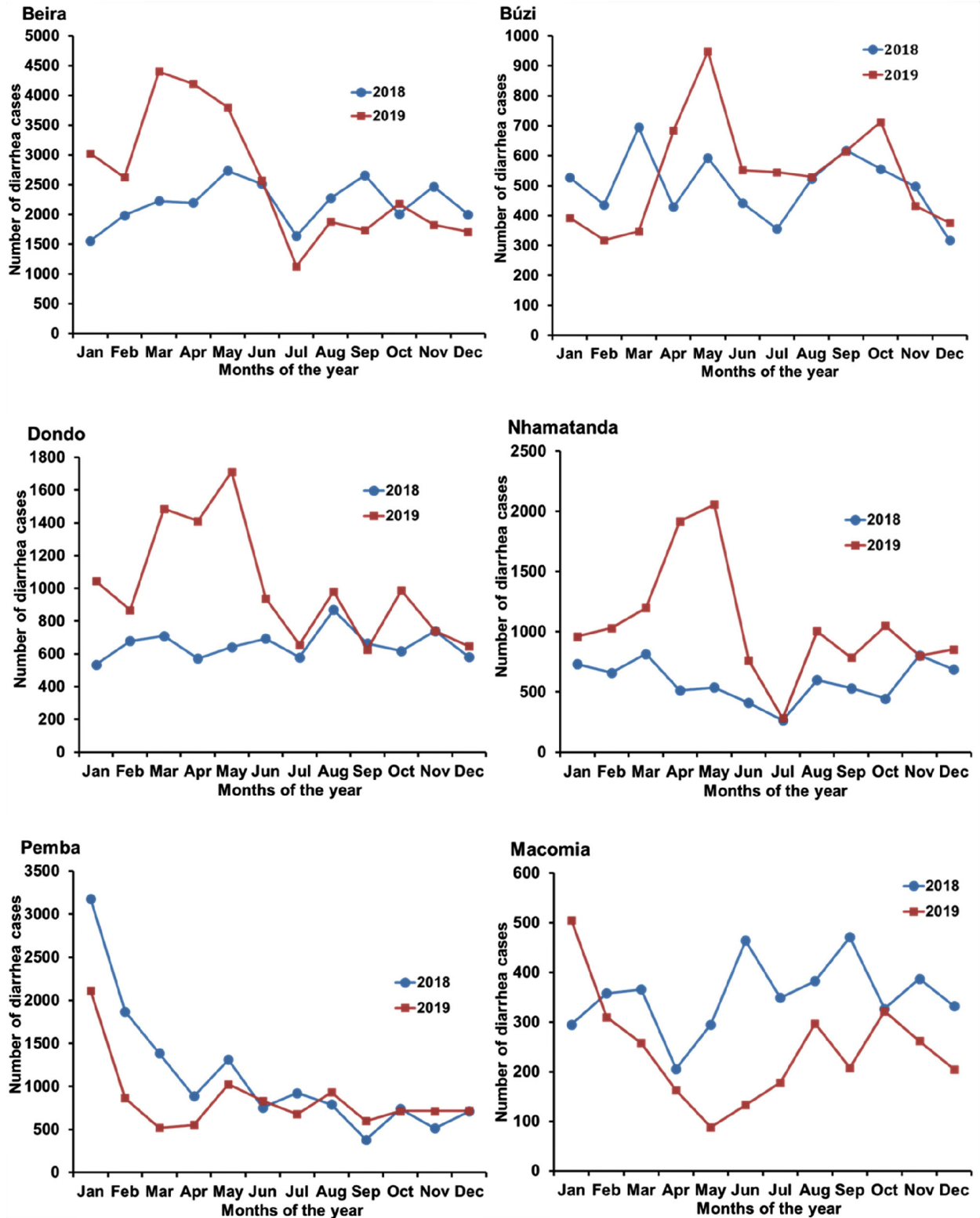

Figure 3 Monthly frequency of diarrhoea cases reported in 2018 and 2019 in Beira, Búzi, Dondo and Nhamatanda districts (Sofala Province) and in Pemba and Macomia districts (Cabo Delgado Province).

acute malnutrition, particularly in districts hit by cyclones and floods. Approximately $42.6 \%$ of children $<5$ years were stunted, with $19 \%$ categorised as underweight. ${ }^{1725} \mathrm{~A}$ high prevalence of malnutrition has also been observed in India following children's exposure to recurrent flooding, ${ }^{44}$ and in Nepal and China following an earthquake. ${ }^{456}$ In addition, a large pellagra outbreak, caused by niacin (vitamin $\mathrm{B}_{3}$ ) and tryptophan deficiencies, was detected in Sofala following Idai. In a case-control study, we found that insufficient consumption of specific food (chicken, meat, eggs, peanuts) prior to the cyclone's arrival was associated with increased susceptibility to disease, suggesting that Idai triggered the pellagra development in a population that already suffered from food insecurity and vitamin deficiency. ${ }^{47}$ Therefore, humanitarian aid can help address the food shortages, but it is not a long-term solution for the malnutrition problems.

\section{Other health challenges}

Despite advances in provision of antiretroviral therapy, ${ }^{4849}$ AIDS remains an important public health issue, with an overall prevalence of $12.6 \%$ among adults (aged 15-49). ${ }^{15}$ Although data are lacking, follow-up and treatment of patients with AIDS and other chronic diseases were likely hampered by the recent cyclones and population resettlement. Other reported health problems for which good epidemiological data are lacking include mental disorders following disasters, with people developing psychiatric problems and even suicidal behaviour following such tragic upheavals. In addition, the flooding resulting from the tropical storms may have also influenced the incidence of vectorborne diseases ${ }^{50}$ particularly in the city of Pemba, ${ }^{5152}$ where the arrival of naive people from other regions in the country may potentially enhance transmission of dengue and other arboviral diseases. 
Table 1 Number of cholera suspected cases and deaths, attack rate, and case fatality ratio by district in the provinces of Sofala (27 March-17 June 2019) and Cabo Delgado (1 May-30 June), Mozambique

\begin{tabular}{lccccc}
\hline Province and district & Population & Cholera cases & Cholera deaths & Attack rate, per 100 000 Case fatality rate (\%) \\
\hline Sofala Province & 1185319 & 6773 & 8 & 571.4 & 0.12 \\
\hline Beira & 465918 & 4750 & 4 & 1019.5 & 0.08 \\
\hline Dondo & 189259 & 1094 & 2 & 578.0 & 0.18 \\
\hline Nhamatanda & 322511 & 795 & 2 & 246.5 & 0.25 \\
\hline Búzi & 207631 & 134 & 0 & 64.5 & 0.0 \\
Cabo Delgado Province & 327828 & 346 & 0 & 105.5 & 0.0 \\
\hline Pemba & 200529 & 203 & 0 & 101.2 & 0.0 \\
\hline Metuge & 86866 & 113 & 0 & 110.1 & 0.0 \\
Mecufi & 40433 & 30 & 0 & 74.2 & 0.0
\end{tabular}

Source of data: mAlert platform, a web-based platform hosted by the Ministry of Health of Mozambique/National Institute of Health.

Available at https://malert.ins.gov.mz/login?next=/advanced-query.

\section{The COVID-19 pandemic}

Since the first COVID-19 case was officially reported in the country on 22 March 2020, the virus spread relatively slowly through the country. However, early in 2021, the number of reported cases exploded, reaching almost 1300 cases per day in the last week of January. As of 16 June 2021, 71764 cases and 844 COVID-19 deaths have been reported nationwide, ${ }^{53}$ but these numbers are probably underestimates given the low capacity for molecular and serological diagnosis in Mozambique.

The expansion of SARS-CoV-2 transmission in Mozambique may have been facilitated by the current living conditions in the country. Almost 2 years after Idai and Kenneth struck, many families still suffer from lack of adequate habitation, as are the people displaced from areas in Cabo Delgado Province following the terrorist attacks. These people now live in overcrowded conditions in relatives' homes, improvised settlements and/or host communities, especially in Pemba (the capital of Cabo Delgado) and its peripheral areas, which are providing shelter for the majority of people escaping the regions where terrorist attacks occur. This overcrowded environment (within households, neighbourhoods and towns) runs counter to the public health recommendations for physical distancing to reduce COVID-19 exposure and transmission, and likely contributed to making Pemba one of the first regions in the country to be severely hit by the virus.

The COVID-19 pandemic further exacerbated the ongoing humanitarian crisis. Social distancing measures, taken to contain the pandemic, prevented the population from engaging in basic livelihood activities and from receiving adequate health assistance. In addition, COVID-19 stressed the health sector even further, likely increasing morbidity and mortality rates from other diseases. Evidence shows, for example, that the COVID-19 pandemic had an impact on the continuity of services for HIV, tuberculosis and malaria, as well as on programmes for prevention of maternal and child mortality in many low-income and middle-income countries in Africa and
Asia. $^{5556}$ The most recent data available on COVID-19 vaccine distribution in Mozambique are from $10 \mathrm{June}$ $2021 .^{57}$ By then, only $1.02 \%$ of Mozambicans had received at least the first dose of COVID-19 vaccine. For comparison, on the same date, $51.56 \%, 35.23 \%, 24.67 \%, 2.73 \%$ and $20.28 \%$ of the populations of the USA, Europe, Brazil, South Africa and the world had received the first dose of vaccine, respectively.

\section{PUBLIC HEALTH PREPAREDNESS AND RESPONSE TO COPE WITH SEQUENTIAL HEALTH CRISIS}

So what happens when such crises overlap in a syndemic scenario? To what extent is the public health sector prepared to tackle this complex combination of challenges? And what can be done to anticipate such events in order to limit their impact?

The growing crisis imposed by the overlapping of natural disasters, terrorism and the COVID-19 pandemic, which increase poverty and social inequalities, requires a critical analysis of the health situation in the country, as well as comprehensive preparation and response plans. Although the MoH sector's strategic plan (Strategic plan of the Health sector (PESS) 2014-2019/2023) ${ }^{58}$ has recognised the negative impacts of natural disasters on health and health services, there continues to be a gap in the definition of disaster preparedness, mitigation, coping and recovery strategies that considers different events (drought, floods and cyclones) which threaten public health. To increase its responsiveness in addressing disaster risk reduction actions, we propose the following:

- Incorporation of sectoral responsibilities and competences at the national, provincial and district levels to face the consequences of disasters. In addition, the health sector needs to strengthen collaborations with other sectors that play an important role in disaster planning and response, such as education, infrastructure, sanitation and agriculture. We learnt from Cyclone Idai that joint intersectoral work aiming at 

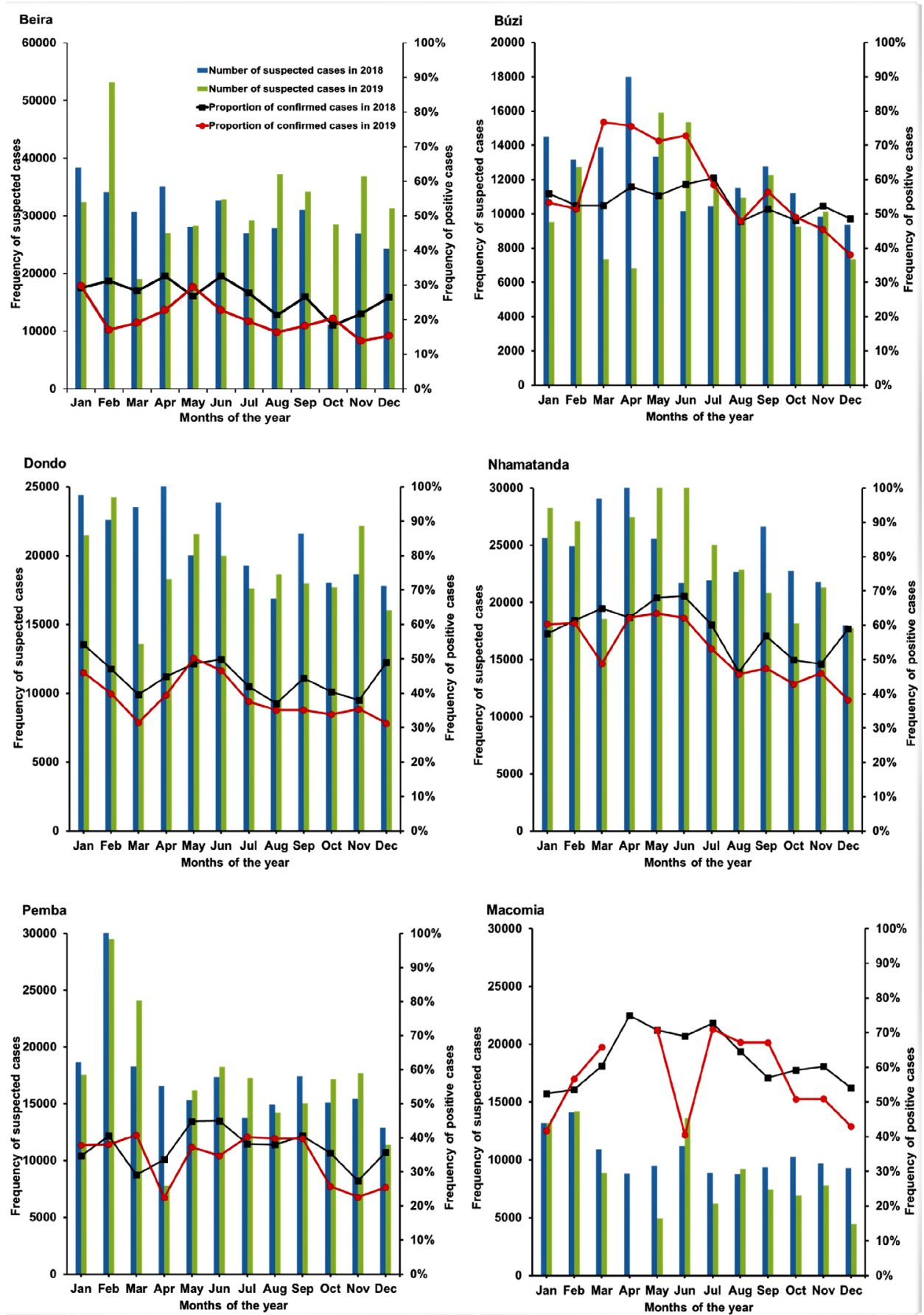

Figure 4 Monthly frequency of suspected and confirmed malaria cases reported in 2018 and 2019 in Beira, Búzi, Dondo and Nhamatanda districts (Sofala Province) and in Pemba and Macomia districts (Cabo Delgado Province).

immediate adoption of preventive measures against cholera was key to containing the outbreak.

- Continuous training of local health personnel to strengthen their capacity to prevent, detect and respond to outbreaks; improvement of health facilities to make them resilient against damage from floods and cyclones; and strengthening laboratory capacity and/or establishing reference laboratories country-wide to conduct serological and molecular tests, sequencing and other examinations, and secure funding for all of these.
- Improvement of the surveillance and monitoring systems, establishing thresholds for early warning, and strengthening collaboration with universities and research institutions nationally and internationally. While the National Institute of Health has increased its research performance in providing scientific evidence to support the political and public health decision-making process at the ministerial level, active participation of Mozambican universities in this process is still limited. 
- Identify and map risk areas, threats (WASH conditions, food and nutrition security, presence of disease vectors), susceptibilities and vulnerable populations; and develop health education actions and strengthen health promotion and preventive and recovery programmes, with community involvement to be adopted continuously.

- Ensure social mobilisation, intersectoral articulation and resource mobilisation for continued investments that prioritise basic health services, which are essential for the most vulnerable groups (eg, interventions to promote health, prevent maternal and child malnutrition).

- Strengthen the extended vaccination programme, which plays such an important role in improving health indicators, especially in maternal and child health; ensure COVID-19 vaccines acquisition, compatible with local logistical capacity (cold chain systems, storage and transportation), and increase the speed of the vaccination process especially among people in vulnerable situations; and ongoing review of priority groups, implementation plan and vaccination coverage according to pandemic progression.

- With the INGD and other sectors, develop joint or specific operational plans aimed at reducing the population's exposure to the risks of diseases and injuries resulting from these disasters.

- For the country's health information systems, adjust or develop more effective and timely reporting tools. This process consists of creating detailed databases, embedded in a comprehensive safety network, and guaranteeing the quality of data for conducting epidemiological analyses. There is also a need for the development of long-term epidemiological surveillance systems for monitoring affected populations, allowing timely identification and provision of information for implementation of specific protective measures.

\section{CONCLUSION}

Cyclones Idai and Kenneth hit the country 3 years after the worst drought recorded in three decades, 2 years after the start of terrorist attacks and 1 year before the COVID-19 pandemic. The impact of these events, coupled with intense population displacement, further exacerbated hunger and can exhaust the resilience capacity of the most vulnerable communities, magnifying longterm health problems. However, the humanitarian crisis does offer an opportunity to assess gaps, discuss ideas and identify actions that can be implemented to create and/or improve the technical and functional capacity of public health in Mozambique. This will depend on strong political commitment and a joint effort by the different actors involved in formulation and implementation of public health policies and on broadening the participation of non-profit and non-governmental organisations, especially those aiming to establish public-private partnerships to extend access to health services throughout Mozambique.
The legal framework in Mozambique organises health services in hierarchically decentralised branches at provincial and district levels, with the supervision of the $\mathrm{MoH}$ at the central level. However, in practice, districts and provinces are still very dependent of the $\mathrm{MoH}$ with regard to health surveillance, provision of secondary and tertiary care, and even for formulation of local health programmes. To further advance decentralisation, it is essential that provinces and districts have more autonomy to raise funds, identify health priorities at the local and regional level, define resource allocation and organise their health programmes. It is also critical to continue empowering the National Health System and enable it to identify needs in advance, plan appropriate responses and gather the necessary resources.

At the planetary level, Mozambique can be viewed as a 'canary in the coal mine', harbingering to the world the synergistic effects of a series of co-occurring anthropogenic and natural disasters. Other regions of the world, and even countries more economically developed, have also faced disasters, exemplified by hurricanes, droughts and immigration pressure in the USA, major droughts and floods in Australia, and severe wildfires and explosive COVID-19 outbreaks in Italy and Spain. It is critical that a diverse set of stakeholders from health and other key sectors, especially in low-income and middle-income countries, which commonly suffer the greatest burden of these events, join efforts at the national levels and with global actors to address these ongoing public health challenges.

Contributors VAM, GSR, ESG and UK conceived this manuscript. VAM wrote the first draft. GSR, UK, ESG and OFI reviewed and edited the manuscript. All authors analysed the work critically and approved the final version.

Funding This work was supported by the National Institute of Health of Mozambique. VAM and GSR received scholarships from the Brazilian National Council for Scientific and Technological Development (CNPq).

Map disclaimer The inclusion of any map (including the depiction of any boundaries therein), or of any geographic or locational reference, does not imply the expression of any opinion whatsoever on the part of BMJ concerning the legal status of any country, territory, jurisdiction or area or of its authorities. Any such expression remains solely that of the relevant source and is not endorsed by BMJ. Maps are provided without any warranty of any kind, either express or implied.

Competing interests None declared.

Patient consent for publication Not required.

Provenance and peer review Not commissioned; externally peer reviewed.

Data availability statement All data relevant to the study are included in this work.

Open access This is an open access article distributed in accordance with the Creative Commons Attribution Non Commercial (CC BY-NC 4.0) license, which permits others to distribute, remix, adapt, build upon this work non-commercially, and license their derivative works on different terms, provided the original work is properly cited, appropriate credit is given, any changes made indicated, and the use is non-commercial. See: http://creativecommons.org/licenses/by-nc/4.0/.

\section{ORCID iDs}

Osvaldo F Inlamea http://orcid.org/0000-0003-3930-7432

Guilherme S Ribeiro http://orcid.org/0000-0002-6798-2059

\section{REFERENCES}

1 INFORM. Country Risk Profile [Internet], 2019. Available: https:// drmkc.jrc.ec.europa.eu/inform-index/INFORM-Risk/Country-Profile/ moduleld/1767/id/386/controller/Admin/action/CountryProfile 
2 et alNhamirre B, Jossai E, Cortez E. Datasheet: Title: The number of internally displaced people in Mozambique has grown by about $2700 \%$ in two years [Internet]., 2020. Available: https://cipmoz.org/ wp-content/uploads/2020/10/The-number-of-internally-1.pdf

3 Singer M, Bulled N, Ostrach B, et al. Syndemics and the biosocial conception of health. Lancet 2017;389:941-50.

4 Horton R. Offline: COVID-19 is not a pandemic. Lancet 2020;396:874.

5 FAO. AQUASTAT country profile - Mozambique. food and agriculture organization of the United nations (FAO). Rome, Italy: FAO, 2016. http://www.fao.org/aquastat/en/countries-and-basins/countryprofiles/country/MOZ

6 GFDRR,WB,RMSI I. Economic vulnerability and disaster risk assessment in Malawi and Mozambique. Available: https://www. preventionweb.net/files/15520_gfdrrecon.vulnerabilitydrrmalawimoz. pdf

7 Global Facility for Disaster Reduction and Recovery (GFDRR). Financial Protection against Disasters in Mozambique [Internet]. 2018. Available: https://reliefweb.int/report/mozambique/financialprotection-against-disasters-mozambique-april-2018

8 INGC GWUU. Recovery from recurrent floods 2000-2013, 2014. Available: https://www.gfdrr.org/sites/default/files/publication/rfcs2014-mozambique.pdf

9 World Bank. Rural population (\% of total population) - Mozambique [Internet], 2021. Available: https://data.worldbank.org/indicator/SP. RUR.TOTL.ZS?end $=2019$ \&locations $=M Z \&$ start $=1960$ \&view $=$ chart

10 Domingues $P$. The health consequences of Mozambican civil war : an anthropometric approach. halshs-00461513 [Internet], 2010. Available: http://ideas.repec.org/p/mse/cesdoc/10010.html

11 Wilson KB. Internally displaced, refugees and returnees from and in Mozambique. Studies on emergencies and disaster relief, 1994: 61.

12 Hanlon J. Mozambique: 'the war ended 17 years ago, but we are still poor'. Conflict, Security \& Development 2010;10:77-102.

13 et alRodríguez R, Engel J, Poncin A. Against the odds Mozambique's gains in primary health care Case study Report [Internet], 2014. Available: https://cdn.odi.org/media/documents/9620.pdf

14 UNECA. Country profile 2016, 2017: 52. https://archive.uneca. org/sites/default/files/uploaded-documents/CountryProfiles/2017/ mozambique en.pdf

15 PROGRAMME UND. Human Development Reports [Internet], 2020. Available: http://hdr.undp.org/en/countries/profiles/MOZ\#

16 Ortiz-Ospina E. Global health, 2016. Available: https:// ourworldindata.org/health-meta

17 World Food Programme. El Niño: Undermining Resilience Implications of El Niño in Southern Africa from a Food and Nutrition Security Perspective [Internet]., 2016. Available: https://documents. wfp.org/stellent/groups/public/documents/ena/wfp282004.pdf?_ga= 2.239285955.1333396570.1610175934-1687339634.1607418387

18 USAID. Climate Risk Profile. Usaid [Internet], 2018: 1-5. https://www. climatelinks.org/sites/default/files/asset/document/2018_USAIDATLAS-Project Climate-Risk-Profile-Mozambique.pdf

19 Kovats R, Bouma M, Haines A. El Niño and Health Protection of the Human Environment. World Heal Organ [Internet], 1999. Available: https://www.who.int/globalchange/publications/en/elnino.pdf

20 Kovats RS, Bouma MJ, Hajat S, et al. El Niño and health. Lancet 2003;362:1481-9.

21 WFP. Report on the RIASCO Action Plan for the El Niño - Induced Drought in Southern Africa, 2017. Available: https://reliefweb.int/ report/world/report-riasco-action-plan-el-ni-o-induced-droughtsouthern-africa-20162017

22 Sida. MOZAMBIQUE MULTIDIMENSIONAL POVERTY ANALYSIS: STATUS AND TRENDS [Internet], 2019. Available: https://sidasewp-files-prod.s3.eu-north-1.amazonaws.com/app/uploads/2020/12/ 01095839/mozambique-mdpa.pdf [Accessed 14 Apr 2021]

23 CARE. El Niño Drought Crisis in Southern Africa [Internet]. Vol. 75, 2016. Available: https://www.care-international.org/files/files/1808 2018SouthernAfricaRegionalFactsheet.pdf

24 HCT (Humanitarian Country Team) \& United Nations Resident, Mozambique CO in. 2018-2019 Mozambique Humanitarian Response Plan Revised following Cyclones Idai and Kenneth, May 2019 (November 2018 - June 2019) [Internet], 2019. Available: https://reliefweb.int/report/mozambique/2018-2019-mozambiquehumanitarian-response-plan-revised-following-cyclones-idai [Accessed 08 Mar 2021].

25 Gobal Network Against Food Crisis. Global Report on Food Crises [Internet]. Food Security Information Network, 2020. Available: https://www.sadc.int/files/8415/8818/9448/GRFC_2020_ONLINE.pdf

26 MISAU, INS O. Tropical Cyclones Idai and Kenneth Mozambique - National Situation Report 4 [Internet], 2019. Available: https:// www.afro.who.int/publications/tropical-cyclones-idai-and-kennethmozambique-national-situation-report-4 [Accessed 14 Apr 2021].
27 OCHA. Southern Africa: Tropical Cyclone Kenneth Flash Update No. 7 (2 May 2019) [Internet], 2019. Available: https://reliefweb.int/ report/mozambique/southern-africa-tropical-cyclone-kenneth-flashupdate-no-7-2-may-2019 [Accessed 08 Mar 2021].

28 SADC. SADC Regional Humanitarian Floods Appeal in Response to Tropical Cyclone IDAI [Internet], 2019. Available: https://reliefweb. int/report/mozambique/sadc-regional-humanitarian-floods-appealresponse-tropical-cyclone-idai-enpt [Accessed 08 Mar 2021].

29 UNDP. Mozambique Cyclone Idai Post-Disaster Needs Assessment (PDNA) [Internet], 2019. Available: https://www.undp.org/ publications/mozambique-cyclone-idai-post-disaster-needsassessment-pdnadna\#modal-publication-download [Accessed 08 Mar 2021].

30 Massarongo-Jona O. O Direito à Saúde como Um direito humano em Moçambique. CIADS 2016;5:152-64 https://www.cadernos. prodisa.fiocruz.br/index.php/cadernos/article/view/348/434

31 World Bank. Physicians (per 1,000 people) - Mozambique [Internet], 2018. Available: https://data.worldbank.org/indicator/SH.MED. PHYS.ZS?locations=MZ [Accessed 09 Apr 2021].

32 UNICEF. Water, sanitation and hygiene (WASH) [Internet], 2017. Available: https://www.unicef.org/mozambique/en/water-sanitationand-hygiene-wash [Accessed cited 2019 Sep 25].

33 GBD Diarrhoeal Diseases Collaborators. Estimates of global, regional, and national morbidity, mortality, and aetiologies of diarrhoeal diseases: a systematic analysis for the global burden of disease study 2015. Lancet Infect Dis 2017:17:909-48.

34 Gujral L, Sema C, Rebaudet S, et al. Cholera epidemiology in Mozambique using national surveillance data. J Infect Dis 2013;208 Suppl 1:S107-14.

35 MISAU1, INS1 O. Tropical Cyclones Idai and Kenneth Mozambique national situation report 5, 2019. Available: https://www.afro.who.int/ sites/default/files/2019-08/SitRep 5_MOZ_3 to 19 Jun 2019_ENG \% 5Bv.1.2\%5D 1.pdf

36 Mabunda S, Casimiro S, Quinto L, et al. A country-wide malaria survey in Mozambique. I. Plasmodium falciparum infection in children in different epidemiological settings. Malar J 2008;7:1-11.

37 IHME. GBD Compare 2018, Mozambique [Internet], 2020. Available: http://www.healthdata.org/mozambique [Accessed 29 Mar 2021].

38 Brown KH. Symposium: nutrition and infection, prologue and progress since 1968: diarrhea and malnutrition. J Nutr 2003;133:336-40.

39 Keusch GT. Symposium: nutrition and infection, prologue and progress since 1968: the history of nutrition: malnutrition, infection and immunity 1,2. J Nutr 2003;133:336-40 https://academic.oup. com/jn/article/133/1/336S/4687573

40 Nyaradi A, Li J, Hickling S, et al. The role of nutrition in children's neurocognitive development, from pregnancy through childhood. Front Hum Neurosci 2013;7:97.

41 Prado EL, Dewey KG. Nutrition and brain development in early life. Nutr Rev 2014;72:267-84.

42 Bahru BA, Bosch C, Birner R, et al. Drought and child undernutrition in Ethiopia: a longitudinal path analysis. PLOS One 2019;14:e0217821.

43 WHO/MISAU/INS. Early Warning and Response System (EWARS) [Internet], 2019. Available: https://malert.ins.gov.mz/login?next=/ advanced-query [Accessed cited $2021 \mathrm{Mar} 30]$.

44 Rodriguez-Llanes JM, Ranjan-Dash S, Degomme O, et al. Child malnutrition and recurrent flooding in rural eastern India: a community-based survey. BMJ Open 2011;1:1-8.

45 Dhoubhadel BG, Raya GB, Shrestha D, et al. Correction to: changes in nutritional status of children who lived in temporary shelters in Bhaktapur municipality after the $2015 \mathrm{Nepal}$ earthquake. Trop Med Health 2020;48:81.

46 Sun J, Huo J, Zhao L, et al. The nutritional status of young children and feeding practices two years after the Wenchuan earthquake in the worst-affected areas in China. Asia Pac J Clin Nutr 2013;22:100-8

47 Mugabe VA, Mahumane A, Semá Baltazar C, et al. Cyclone Idai as a trigger for pellagra outbreak in Nhamatanda, Mozambique: a CaseControl study. Am J Trop Med Hyg 2021;104:2233-7.

48 Audet CM, Burlison J, Moon TD, et al. Sociocultural and epidemiological aspects of HIV/AIDS in Mozambique. BMC Int Health Hum Rights 2010;10:15.

49 UNAIDS. Mozambique [Internet], 2021. Available: https://www. unaids.org/en/regionscountries/countries/mozambique [Accessed 18 Apr 2021]

50 Mugabe VA, Ali S, Chelene I, et al. Evidence for chikungunya and dengue transmission in Quelimane, Mozambique: results from an investigation of a potential outbreak of Chikungunya virus. PLOS One 2018;13:1-13. 
51 Massangaie M, Pinto G, Padama F, et al. Clinical and epidemiological characterization of the first recognized outbreak of dengue virus-type 2 in Mozambique, 2014. Am J Trop Med Hyg 2016;94:413-6.

52 Oludele J, Lesko B, Mahumane Gundane I, et al. Dengue virus serotype 2 established in northern Mozambique (2015-2016). Am J Trop Med Hyg 2017;97:1418-22.

53 Dong E, Du H, Gardner L. An interactive web-based dashboard to track COVID-19 in real time. Lancet Infect Dis 2020;20:533-4.

54 JHU. COVID-19 Dashboard by the Center for Systems Science and Engineering (CSSE) at Johns Hopkins University [Internet], 2021. Available: https://coronavirus.jhu.edu/map.html [Accessed 12 May 2021].

55 Global Fund. The Impact of Covid-19 on Hiv, Tb and Malaria Services and Systems for Health : a Snapshot From 502 Health
Facilities. Glob Fund to Fight AIDS Malaria, Tuberc [Internet]., 2021. Available: https://reliefweb.int/sites/reliefweb.int/files/resources/ covid-19_2020-disruption-impact_report_en.pdf

56 Chmielewska B, Barratt I, Townsend R, et al. Effects of the COVID-19 pandemic on maternal and perinatal outcomes: a systematic review and meta-analysis. Lancet Glob Health 2021;9:e759-72.

57 Mathieu E, Ritchie H, Ortiz-Ospina E. Statistics and Research: Coronavirus (COVID-19) Vaccinations [Internet]. ourworldindata.org, 2021. Available: https://ourworldindata.org/covid-vaccinations

58 MISAU. Plano Estratégico do Sector da Saúde - PESS 2014-2019 [Internet], 2013. Available: file:///C:/Users/LENOVO/Downloads/ Plano Estratgico do Sector da Sade 2014 - 2019 (2).pdf 